ARTICLE

https://doi.org/10.1038/s41467-018-07923-2

\title{
The transcription factor STAT5 catalyzes Mannich ligation reactions yielding inhibitors of leukemic cell proliferation
}

Ee Lin Wong ${ }^{1}$, Eric Nawrotzky ${ }^{1}$, Christoph Arkona1, Boo Geun Kim², Samuel Beligny², Xinning Wang ${ }^{1}$, Stefan Wagner ${ }^{1}$, Michael Lisurek ${ }^{2}$, Dirk Carstanjen² \& Jörg Rademann (1) 1,2

Protein-templated fragment ligations have been established as a powerful method for the assembly and detection of optimized protein ligands. Initially developed for reversible ligations, the method has been expanded to irreversible reactions enabling the formation of super-additive fragment combinations. Here, protein-induced Mannich ligations are discovered as a biocatalytic reaction furnishing inhibitors of the transcription factor STAT5. STAT5 protein catalyzes multicomponent reactions of a phosphate mimetic, formaldehyde, and $1 \mathrm{H}$-tetrazoles yielding protein ligands with greatly increased binding affinity and ligand efficiency. Reactions are induced under physiological conditions selectively by native STAT5 but not by other proteins. Formation of ligation products and (auto-)inhibition of the reaction are quantified and the mechanism is investigated. Inhibitors assembled by STAT5 block specifically the phosphorylation of this protein in a cellular model of acute myeloid leukemia (AML), DNA-binding of STAT5 dimers, expression of downstream targets of the transcription factor, and the proliferation of cancer cells in mice.

\footnotetext{
${ }^{1}$ Department of Biology, Chemistry and Pharmacy, Medicinal Chemistry, Freie Universität Berlin, Königin-Luise-Str. 2+4, 14195 Berlin, Germany.

${ }^{2}$ Department of Medicinal Chemistry, Leibniz Institut für Molekulare Pharmakologie (FMP), Robert-Rössle-Str. 10, 13125 Berlin, Germany. Correspondence and requests for materials should be addressed to J.R. (email: joerg.rademann@fu-berlin.de)
} 
$\mathrm{n}$ protein-templated fragment ligations, proteins catalyze the formation of ligands with enhanced binding affinity from bound reactive fragments, thereby integrating chemical synthesis of protein ligands and modulation of protein activity in one single step ${ }^{1-6}$. The chemical space accessible by proteintemplated reactions, however, is still strongly limited. Whereas most applications so far have employed reversible ${ }^{7-10}$, i.e., dynamic ligation reactions, few reactions have been used for the irreversible ${ }^{11-15}$ formation of stable protein ligands by proteintemplated reactions, mostly employing dipolar cycloaddition reactions ${ }^{13,14}$. Recently, amide bonds, a privileged fragment linkage in bioactive molecules, have been accessed by proteintemplated chemistry ${ }^{16}$. Evidently, it would be a major expansion of the chemical space populated by protein-dependent reactions, if multicomponent reactions could be employed for ligand formation-possibly exploiting alternative mechanisms ${ }^{9}$.

Here, Mannich ligations, three-component reactions of an amine, aldehyde, and $\mathrm{N}$ - or $\mathrm{C}$-nucleophile, are investigated as protein-catalyzed reactions for discovering protein ligands. As a target, the transcription factor STAT5 (STAT = signal transducers and activators of transcription) is selected representing a central hub in the signaling of numerous cancer cell types. A small heterocyclic phosphate-mimetic binding to STAT5 with low affinity is discovered from a fragment screen and used as a starting point for fragment expansion using protein-induced multicomponent reactions. Mannich ligation products with improved affinity for STAT5 are assembled by the protein and selectivity, $\mathrm{pH}$-dependence, and the biocatalytic mechanism of this protein-induced reaction are investigated. Furthermore, selectivity and functional efficacy of the inhibitors are validated for isolated proteins, in complex cell lysates, in living cells and finally in mice in order to evaluate the functional potential of protein ligands generated by protein-induced ligation.

\section{Results}

Target selection. The transcription factor STAT5 was selected as a target owing to its central role in the signaling of numerous cancer cell types ${ }^{17,18}$. STAT5 is expressed in two closely related forms, STAT5a and b, with $94 \%$ identity of the amino-acid sequence. STAT5 contains an $\mathrm{SH} 2$ domain, which is responsible for the binding of the protein to phosphotyrosine-containing peptide sequences of kinases, resulting in the phosphorylation at tyrosine 694/699. Phospho-STAT5 dimerizes via its SH2 domain and translocates into the nucleus ${ }^{19}$. There, p-STAT5 dimers bind to genomic promoter sequences inducing the transcription of target genes. In consequence, ligands of STAT-SH2 domains are able to suppress STAT signaling and have been recognized as potential anticancer drugs. STATs, however, have been described as difficult pharmacological targets ${ }^{20}$. Although highly potent peptide ligands have been reported for the STAT-SH2 domains ${ }^{21,22}$, these phosphopeptide mimetics usually fail to provide significant cellular activity. Several cellularly active small molecule inhibitors of STAT5 have been developed as well, however, none of these have been based on protein-induced reactions yet ${ }^{23-25}$.

Discovery and validation of a phosphate-mimetic fragment. Binding of fragments to the recombinantly expressed STAT5b$\mathrm{SH} 2$ domain fused to maltose-binding protein (MBP) as affinity tag was recorded by measuring fluorescence polarization (FP) of the carboxyfluoresceine-labeled phosphotyrosine octapeptide $1\left(K_{D}=55 \mathrm{~nm}\right)$ (Fig. 1a) ${ }^{21}$. A collection of 17,000 fragments and fragment combinations composed in accordance with the substructure composition of the World Drug Index (WDI) ${ }^{26}$ was screened for inhibiting the phosphopeptide-STAT5b interaction. Primary amine fragments were tested in the FP assay in the presence of electrophilic phosphotyrosine mimic 2 as described earlier for protein tyrosine phosphatases (PTP) in order to distinguish secondary site binders that enhance the inhibition of 2 from inhibitors that are not affected by $2^{5,21}$. From the second group, one fragment, 4-amino-furazan-3-carboxylic acid $3(\mathrm{M}=$ $129 \mathrm{~g} \mathrm{~mol}^{-1}$, Fig. 1a) displayed a $K_{D}$ value of $420 \mu \mathrm{M}$, corresponding to the ligand efficiency of $2.1 \mathrm{~kJ} \mathrm{~mol}^{-1}$ per nonhydrogen atom, higher than that of the nanomolar phosphopeptide $\mathbf{1}$, the phosphotyrosine-mimetic 2 , and the best reported STAT5 inhibitors ${ }^{23-25}$. Ligands with such high ligand efficiency are rather found for enzymatic binding pockets than for protein-protein interaction sites and thus fragment $\mathbf{3}$ was selected for further validation ${ }^{27}$. Binding of 3 to STAT5b-SH2 was confirmed using the thermofluor assay ${ }^{28,29}$, a thermal shift assay (TSA), as an independent biophysical assay. Binding of fragment 3 augmented the melting point of STAT5 by $\Delta T_{m}$ of $3{ }^{\circ} \mathrm{C}$ (Supplementary Figure 1). Potential binding modes of the phosphotyrosine $\mathbf{2}$ and the fragment hit $\mathbf{3}$ were scrutinized using a homology model of STAT5b derived from the crystal structure of STAT5a (PDB:1Y1U [https://doi.org/10.2210/pdb1Y1U/pdb]) for molecular docking (Fig. 1b, c) ${ }^{30}$. The phosphotyrosine binding site in the STAT5-SH2 domain is shallow compared with the deeper binding pockets of $\mathrm{PTP}^{31,32}$, coordinating phenyl phosphate 2 by only two amino-acid residues, Arg618 and Ser622. As a

1: $5-C F-G{ }^{*}$ LSLPPW-NH ${ }_{2}\left(K_{l}=55 \mathrm{nM}\right)$

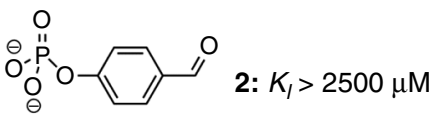<smiles>Nc1nonc1C(=O)O</smiles>

3: $K_{l}=420 \mu \mathrm{M}$

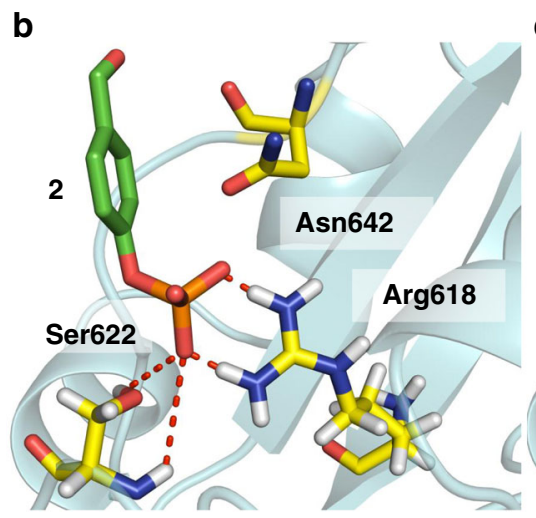

C

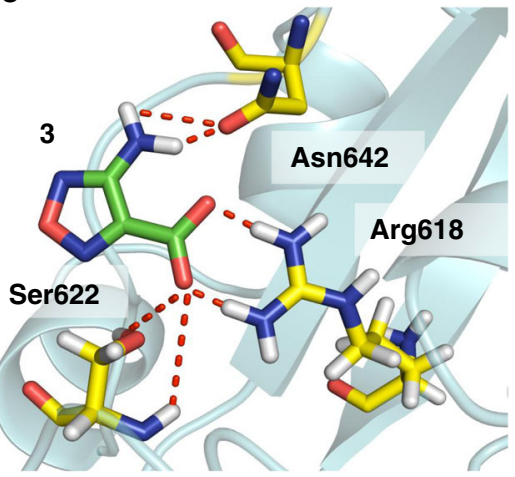

Fig. 1 Discovery of phosphate-mimetic fragment 3. a Fluorescently labeled phosphotyrosine peptide $\mathbf{1}$ was used in an FP assay for the screening of a fragment library furnishing 4-amino-furazan-3-carboxylic acid $\mathbf{3}$ as a phosphate-mimetic ${ }^{21}$. Phosphotyrosine-mimetic fragment 4-formyl-phenyl phosphate $\mathbf{2}$ was employed to investigate fragment hits for second site binding. b-c Molecular docking results of fragments $\mathbf{2}$ and $\mathbf{3}$ into homology model of human STAT5b-SH2 domain, generated from the published structure of STAT5a (PDB accession codes, $1 \mathrm{Y} 1 \mathrm{U}$ [http://dx.doi.org/10.2210/pdb1Y1U/pdb]) ${ }^{30}$. Hydrogen bonds with key residues in the hydrophilic binding pocket of the STAT5-SH2 domain were illustrated as red dashed lines 
a

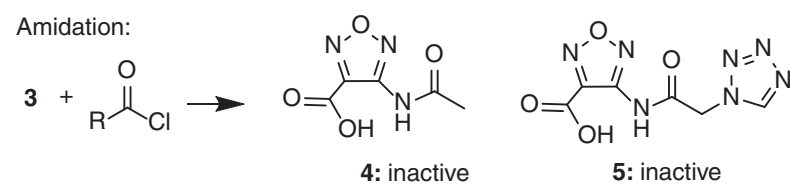

b Mannich ligation:

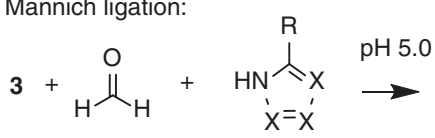

$=\mathrm{OH}_{\mathrm{N}=\mathrm{N}}^{\mathrm{O}}$

6: $191 \mu \mathrm{M}$<smiles>O=C(O)c1nonc1NCn1nnc2ccccc21</smiles>

7: $189 \mu \mathrm{M}$

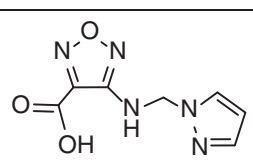

8: $122 \mu \mathrm{M}$

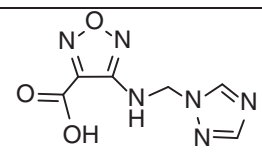

9: $48 \mu \mathrm{M}$<smiles>O=C(O)c1nonc1NCn1cnnn1</smiles>

$10: 1.4 \mu \mathrm{M}$<smiles>O=C(O)c1nonc1NCn1nnnc1-c1ccccc1</smiles>

11: $1.4 \mu \mathrm{M}$<smiles>O=C(O)c1nonc1NCn1nnnc1-c1cccc(C(F)(F)F)c1</smiles>

12: $0.9 \mu \mathrm{M}$

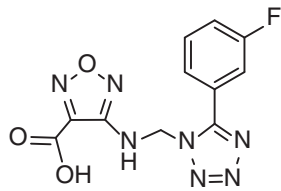

13: $0.6 \mu \mathrm{M}$<smiles>O=C(O)c1nonc1NCn1nnnc1-c1cccc(OC(F)(F)F)c1</smiles>

14: $3.0 \mu \mathrm{M}$<smiles>O=C(O)c1nonc1NCn1nnnc1-c1ccc(F)cc1</smiles>

15: $3.4 \mu \mathrm{M}$

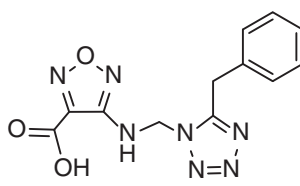

16: $2.9 \mu \mathrm{M}$<smiles>O=C(O)c1nonc1NCn1nnnc1-c1ccc(-c2ccccc2)cc1</smiles>

17: $0.8 \mu \mathrm{M}$

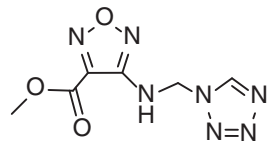

18: $37 \mu \mathrm{M}$<smiles>CC(=O)OC(C)OC(=O)c1nonc1NCn1cnnn1</smiles>

19: $48 \mu \mathrm{M}$

Fig. 2 Expansion of fragment $\mathbf{3}$ through protein-induced reactions. a Amidation of $\mathbf{3}$ yielded compounds $\mathbf{4}$ and $\mathbf{5}$, which were inactive in the FP assay. b Mannich ligation was investigated as an alternative fragment expansion method to obtain the active compounds 6-19 containing a linker with reduced steric hindrance and better structural flexibility

a result, the benzene ring of $\mathbf{2}$ is not buried in a cavity like in the case of PTPs but rather exposed to the solvent at the protein surface. Binding of fragment $\mathbf{3}$ is mediated by the Coulomb interaction between the carboxylate anion and the cation of protonated Arg618 and H-bonds involving Arg618, Ser622, and Asn642.

Fragment expansion via protein-induced Mannich ligations. First, the discovered phosphate-mimetic 3 was expanded by amidation (Fig. 2a), a reaction recently introduced to proteintemplated fragment ligations ${ }^{16}$. The $N$-acetyl derivative $\mathbf{4}$ and all other tested amides including $\mathbf{5}$, however, were inactive in the FP assay. In order to reduce the steric demand from a carbonyl to the more flexible methylene linkage, the Mannich ligation was investigated as fragment expansion method (Fig. 2b). Fragment 3 was found to react readily with formaldehyde (FA) and various $\mathrm{N}$-heterocycles in aqueous buffer at $\mathrm{pH} 5.0$ at room temperature yielding Mannich ligation products, whereas no reaction was observed without protein at $\mathrm{pH}$ 7.4. In order to implement protein-dependent Mannich ligations, the compatibility of the reaction with the protein MBP-STAT5b-SH2 and with the FP assay was investigated. 3-( $N$-Morpholino)-propane sulfonic acid (MOPS, $50 \mathrm{~mm}, \mathrm{pH} 7.4$ ) was used as a buffer containing no primary and secondary amines that could interfere with the reaction. FP of MBP-STAT5b-SH2 (125 nM) with peptide 1 (10 nM) was recorded in the presence of increasing concentrations of $\mathrm{FA}$ at $\mathrm{pH}$ 7.4. No change of FP was observed at concentrations up to $250 \mu \mathrm{m} \mathrm{FA}$, whereas at higher concentrations, FP values increased considerably (Fig. 3a). Likewise, up to $250 \mu \mathrm{m}$ no effect of FA on the melting point of STAT5b-SH2 was recorded in the TSA, although higher FA concentrations reduced the intensity of the fluorescence signal, suggesting interference of FA with the fluorescent dye (Fig. 3b). For in situ Mannich ligation assays, fragment 3 was incubated with one hetaryl nucleophile and FA (all $250 \mu \mathrm{M}$ ) per microtiter plate-well in water resulting in $\mathrm{pH}$ 5.0. After $12 \mathrm{~h}$ incubation at room temperature, protein MBPSTAT5b (125 nм in 50 mм MOPS buffer $\mathrm{pH}$ 7.4) with the peptide probe $\mathbf{1}$ were added and further incubated for $15 \mathrm{~min}$ before FP was recorded. Several of the added heterocycles led to substantially decreased FP values-suggesting the formation of a Mannich ligation product as inhibitor of STAT5b with increased affinity. Active Mannich ligation products were re-synthesized, purified, and tested in the FP assay (Fig. 2b, Supplementary Figures 11-13). Remarkably, the addition of five-membered N-heterocycles ("azoles") to the formimine of fragment 3 led to strongly enhanced inhibition of STAT5b. The 1,2,3-triazol-1-yl product 6 as well as the benzo-1,2,3-triazol-1-yl 7 increased the affinity by a factor of $>2$, pyrazol-1-yl $8>$ threefold, 1,2,4-triazol1 -yl $9>$ ninefold and tetrazol-1-yl 10300 -fold resulting in a $K_{I}$ of $1.4 \mu \mathrm{M}$ (Supplementary Figure 2). The reaction with 5-substituted tetrazoles yielded strongly active inhibitors 11-17, some even with submicromolar affinities, including 4-(5-phenyl-tetrazol-1yl-methylamino)-furazane-3-carboxylate $11(1.4 \mu \mathrm{M}), \quad 5$-(3-trifluoromethyl-phenyl)- $\mathbf{1 2} \quad(0.9 \mu \mathrm{M}), \quad$ 5-(3-fluorophenyl) $\quad \mathbf{1 3}$ $(0.6 \mu \mathrm{M})$, 5-benzyl $16(2.9 \mu \mathrm{M})$, and 5-biphenyl $17(0.8 \mu \mathrm{M})$. Esters of the furazane carboxylic acid $(\mathbf{1 8}, \mathbf{1 9})$ were prepared as prodrug derivatives. 4-(Tetrazolyl-1-methylamino)-furazan-3-carboxylic acid $\mathbf{1 0}$ is the STAT5 inhibitor with the highest ligand efficiency of $2.23 \mathrm{~kJ} \mathrm{~mol}^{-1}$ per non-hydrogen atom. All starting azoles like tetrazole 25 were completely inactive at concentrations of $5 \mathrm{~mm}$, thus the inhibitors constitute examples of super-additive fragment combinations. As a consequence, the observed protein-dependent ligation reaction did not proceed as a proteintemplated reaction, that requires the binding of both reacting fragments to the protein. 


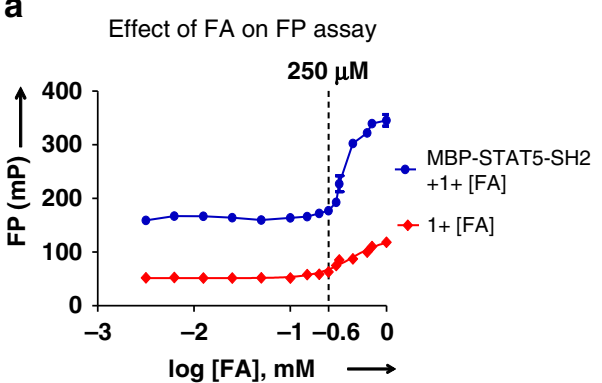

C

Protein-induced formation of 10 in FP

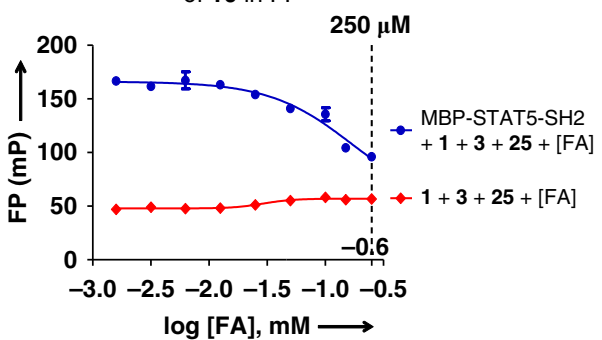

b

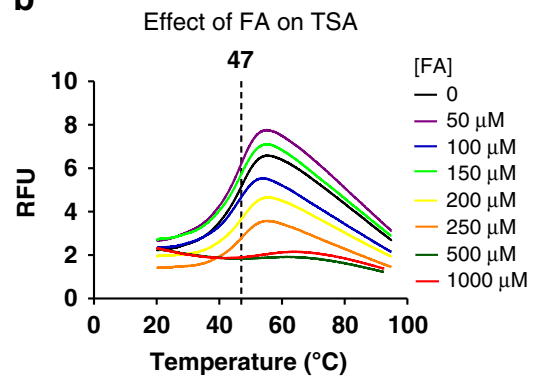

d

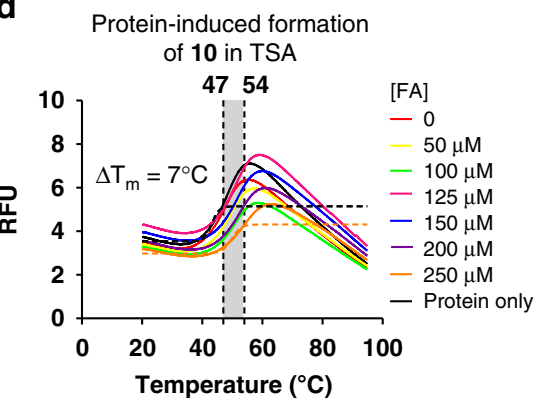

e

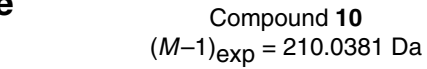

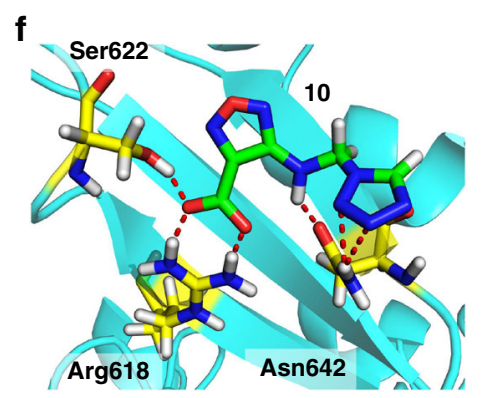
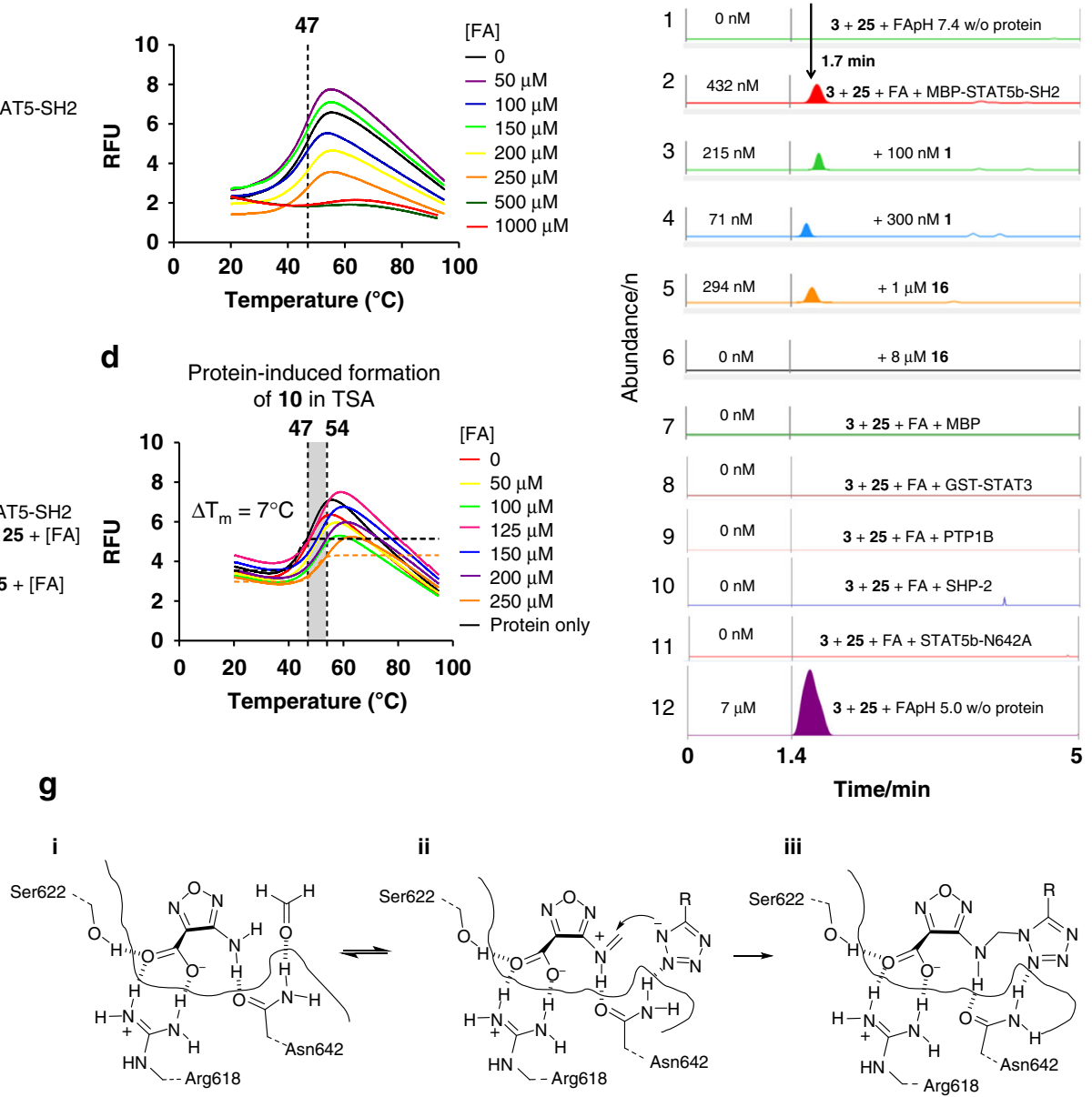

\begin{tabular}{|l|l|l|}
7 & $0 \mathrm{nM}$ & $3+25+\mathrm{FA}+\mathrm{MBP}$ \\
\hline $\mathbf{3}$ & $0 \mathrm{nM}$ & $\mathbf{3}+\mathbf{2 5}+\mathrm{FA}+$ GST-STAT3 \\
\hline
\end{tabular}

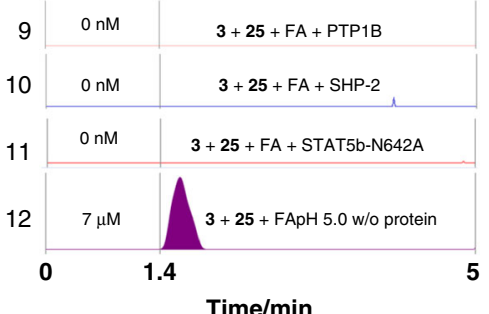

iii

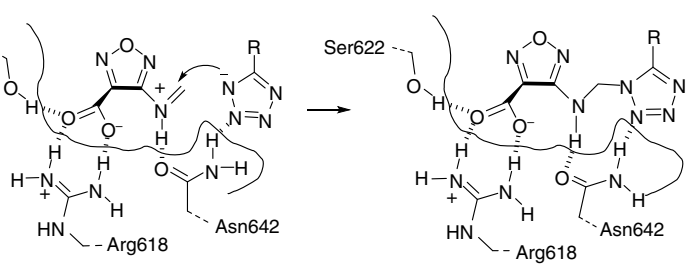

Fig. 3 Assembly of STAT5 inhibitor 10 through protein-induced Mannich ligations. a FA was tolerated at up to $250 \mu \mathrm{M}$ in the FP assay of MBP-STAT5b-SH2 $(n=3)$. b FA did not affect the STAT5b protein stability in the TSA at $\leq 250 \mu \mathrm{M}$ (data shown are one representative of $n=3$ ). $\mathbf{c}$ Protein-induced formation of $\mathbf{1 0}$ in the FP assay with increasing FA concentrations $(n=3)$. d Protein-induced formation of $\mathbf{1 0}$ from fragments $\mathbf{3}$ and $1 H$-tetrazole $\mathbf{2 5}$ with increasing FA concentrations in the TSA $\left(\Delta T_{m}=7^{\circ} \mathrm{C}\right.$ ) (data shown are one representative of $n=3$ ). e Formation of 10 detected in the HPLC-QTOF-MS. 1: No formation of $\mathbf{1 0}$ from FA, fragments $\mathbf{3}$ and $\mathbf{2 5}$ (all $250 \mu \mathrm{M}$ ) at pH 7.4 in MOPS buffer without protein. 2: Protein-induced formation of compound $\mathbf{1 0}$ with protein MBPSTAT5b-SH2 (250 nM) at pH 7.4. 3-6: Inhibition of protein-induced formation of 10 by peptide $\mathbf{1}(3,4)$ or inhibitor $\mathbf{1 6}(5,6)$. 7,8: No formation of compound 10 in the presence of Maltose Binding Protein $(1 \mu \mathrm{m})$ or GST-STAT3 $(250 \mathrm{~nm})$. 9-11: Compound 10 was not formed in the presence of phosphatases, SHP2 (250 nM) and PTP1B (250 nM) nor in the presence of mutant STAT5b-N642A at pH 7.4 in MOPS buffer. 12: Formation of compound 10 at pH 5.0 without protein. Data shown are one representative example of $n=3$. $\mathbf{f}$ D-binding model of the STAT5b:10 complex. Hydrogen bonds are illustrated as red dashed lines. $\mathbf{g}$, Mechanism of the protein-induced formation of $\mathbf{1 0}$ from $\mathbf{3}$ with FA and $\mathbf{2 5}(\mathrm{R}=\mathrm{H})$. (i) Binding of $\mathbf{3}$ via Arg618, Ser622, and Asn642, activation of FA with Asn642. (ii) Activation of the forminium cation of 3, coordination of the incoming tetrazolium anion of $\mathbf{2 5}$ by Asn642 leads to formation of Mannich ligation product 10 (iii). Error bars denote mean \pm S.D

Mechanistic analysis of the protein-induced reactions. Proteincatalyzed reactions of fragment $\mathbf{3}$ with FA and $1 \mathrm{H}$-tetrazole $\mathbf{2 5}$ were investigated by using the binding assays (FP, TSA), and high-performance liquid chromatography-mass spectrometry (HPLC-MS) analysis. Incubation of fragments 3 and $25(250 \mu \mathrm{M}$ each) with MBP-STAT5b-SH2 (250 nM) with increasing concentrations of FA at $\mathrm{pH} 7.4$ led to decreased FP values, suggesting the formation of an inhibitor (Fig. 3c). The protein-induced formation of a STAT5 inhibitor was confirmed in the TSA: Incubation of fragments $\mathbf{3}$ and $\mathbf{2 5}$ with increasing concentrations of FA and the protein resulted in a shift of the protein's melting point $\Delta T_{m}$ by $7^{\circ} \mathrm{C}$ (Fig. $3 \mathrm{~d}$ ). High-resolution HPLC-QTOF-MS analysis was employed to quantify Mannich ligation product 10 formed with or without protein present (Fig. 3e). At pH 7.4, absolutely no inhibitor was formed from 3,25 , and FA, if
MBP-STAT5-SH2 protein was not present (trace 1). With $250 \mathrm{~nm}$ MBP-STAT5-SH2 in the buffer at $\mathrm{pH} 7.4,432 \mathrm{~nm}$ of $\mathbf{1 0}$ were formed over $24 \mathrm{~h}$ (average of three independent experiments). The protein-dependent reaction was saturated after $24 \mathrm{~h}$, no significant changes in product concentration were observed between 24 and $48 \mathrm{~h}$ reaction time-suggesting product inhibition of the ligation reaction. Addition of phosphopeptide 1 or inhibitor $\mathbf{1 6}$ to the protein-induced reaction suppressed the formation of $\mathbf{1 0}$ completely or partly in a concentration-dependent manner (traces 3-6). If instead of the MBP-STAT5-SH2 protein only the protein tag MBP $(1 \mu \mathrm{M})$ or the catalytic domains of tyrosine phosphatases PTP1B or SHP2 $(250 \mathrm{nM})$ were added, no product was formed at all (traces 7,9,10). In contrast, incubation of reagents 3, 25, and FA at pH 5.0 led with or without protein to the formation of $7 \mu \mathrm{M}$ of inhibitor $\mathbf{1 0}$ in a protein-independent 
background reaction (trace 12). Similar data were obtained for the protein-dependent reaction of fragments 3, FA, and benzyltetrazole $\mathbf{2 6}$ although traces of a background reaction were observed in this case (Supplementary Figure 3). In contrast, no protein-dependent reaction was observed when replacing the $1 \mathrm{H}$ tetrazoles by 1,2,4-triazole (Supplementary Figure 3).

Molecular docking suggested that the large increase in binding affinity of compound $\mathbf{1 0}$ was contributed by expansion of the binding interaction into the adjacent amphiphilic pocket containing residues Trp641, Leu643, and Met639 via hydrophobic contacts. The H-bond, between the 4-amino group of $\mathbf{1 0}$ and the carbonyl of Asn642 was retained and possibly enforced by the higher polarity of the NH-bond in $\mathbf{1 0}$ (Fig. 3f). An additional $\mathrm{H}$-bond was proposed by BINding ANALyzer (BINANA) between the tetrazole ring and the amide- $\mathrm{NH}_{2}$ of Asn642 and strengthened the binding of compound $\mathbf{1 0}$ in the binding pocket ${ }^{18,23,33,34}$. In order to challenge the postulated importance of Asn642 for the reactivity of fragment 3 with STAT5b-SH2, the fragment ligation of $3, \mathrm{FA}$, and $1 H$-tetrazole at $\mathrm{pH} 7.4$ was investigated with GST-STAT3, a protein without Asn in the otherwise similar phosphotyrosine recognition site (Fig. 3, trace 8). With STAT3 instead of STAT5b absolutely no fragment ligation product was formed. In addition, the mutant MBPSTAT5b-SH2 N642A was generated by site-directed mutagenesis. The mutant protein displayed strongly reduced binding affinity to peptide 1 with $K_{D}$ of ca. $5 \mu \mathrm{M}$ (instead of $55 \mathrm{~nm}$ for the wildtype) (Supplementary Figure $2 \mathrm{~g}$ ). Binding of the peptide was inhibited by compound 10 with an $I C_{50}$ of $30 \mu \mathrm{M}$ (instead of $1.5 \mu \mathrm{M}$ for the wildtype) (Supplementary Figure 2h). Accordingly, the conditions of the fragment ligation reaction yielded no product with the mutant protein as well. Plausibly, the side chain carbonyl group of Asn 642 binds to the amino group of compound 3 via accepting an $\mathrm{H}$-bond (Fig. 3g). As a result, the amide- $\mathrm{NH}_{2}$ of Asn642 is free to coordinate and activate the incoming $\mathrm{FA}$ as an $\mathrm{H}$-bond donor, leading to the formation of the formiminium derivative of $\mathbf{3}$, which is again stabilized by its $\mathrm{H}$-bond to the Asn-carbonyl. Next, the amide- $\mathrm{NH}_{2}$ could coordinate the incoming $1 \mathrm{H}$-tetrazolium ion which reacts to the observed ligation product 10 .

Specificity of STAT5 inhibitors. Compound $\mathbf{1 0}$ was tested with closely related STAT3 and the catalytic domain of protein tyrosine phosphatase SHP2 (PTPN10) and at concentrations up to $1 \mathrm{~mm}$ no binding or inhibition was observed (Supplementary Figure 4). Next, phosphorylated STAT-dimers were extracted from nuclei of BaF3/FLT3-ITD cells and binding of STAT1, 3, 5a, and $5 \mathrm{~b}$ to DNA was detected using an enzyme-linked immunosorbent assay (ELISA) specific for the respective protein-DNAcomplexes. Compounds 3, 10, and 16 inhibited formation of the DNA complex of STAT5a and STAT5b, but not of STAT1 and STAT3 (Fig. 4b). Likewise, inhibition of the STAT5:DNA complex by compound $\mathbf{1 0}$ was detected in the electro mobility shift assay (EMSA) (Fig. 4c). The specificity of compound 10 was further investigated in complex cell lysates using cellular thermal shift assays (CETSA) (Fig. 4d) ${ }^{35}$. Compound 10 bound to isolated MBP-STAT5b-SH2 shifting the melting temperature $\left(T_{m}\right)$ by $9{ }^{\circ} \mathrm{C}$ (Fig. 4a). BaF3/FLT3-ITD cell lysates were incubated with 10 and exposed to a temperature gradient from $43-73^{\circ} \mathrm{C}^{36}$. Supernatants were analyzed by gel electrophoresis and immunoblotting was performed with STAT5a/b antibodies. Inhibitor $\mathbf{1 0}$ shifted the melting temperatures of STAT $5 \mathrm{a} / \mathrm{b}$ by 5 and $8{ }^{\circ} \mathrm{C}$, respectively, indicating the thermal stabilization of STAT5 proteins through ligand binding in cell lysates (Fig. 4d, e).

The specific interaction of inhibitor 10 with STAT5 was further challenged by interfering with the photo-crosslinking of STAT5b$\mathrm{SH} 2$ and the dual-labeled STAT5-binding peptide 5-CF-K(biotin)
GpcFLSLPPW-NH 27 (CF = carboxyfluorescein, $p c F=$ phosphono-carboxy-phenylalanine $)^{21}$. Peptide 27 was demonstrated to photo-crosslink STAT5b after being exposed to UV irradiation at $365 \mathrm{~nm}$ and $\mathbf{1 0}$ suppressed the photo-crosslinking in a concentration-dependent manner (Supplementary Figure 4). When peptide 27 was incubated with BaF3/FLT3-ITD cell lysate, irradiated for $15 \mathrm{~min}$ at $4{ }^{\circ} \mathrm{C}$ and subjected to pull-down using avidin beads, compound $\mathbf{1 0}$ repressed STAT5-crosslinking by displacing peptide 27 competitively in the complex lysate (Fig. 4f).

Validation of STAT5 inhibitors in living cells and animals. The biological activity of inhibitors was studied in a cellular disease model using the murine pro-B-cell line BaF3 stably transfected with the internal tandem duplication (ITD) mutation of the human FLT3 receptor (FLT3-ITD) ${ }^{37}$. In these cells, STAT5 is constitutively phosphorylated without cytokine activation. As the FLT3-ITD mutation is found in 35\% of AML patients, it can be considered as a relevant model for this disease ${ }^{38}$.

At first, STAT5 phosphorylation at tyrosine residues (Tyr694/ Tyr699) was investigated. 5-Aryl-substituted derivatives like 11-13 could not be tested in cells as they precipitated in buffer. Compounds 10, 16, and 18 were dissolved in dimethylsulphoxide (DMSO) $(20 \mathrm{~mm}$ ) and added to BaF3/FLT3-ITD cells. After $6 \mathrm{~h}$ cells were harvested to determine the level of STAT5 phosphorylation using phosphotyrosine-specific antibodies. The strongest inhibition was observed for compound 16 with $>50 \%$ reduction of STAT5 phosphorylation at $25 \mu \mathrm{M}$ (Fig. 5a). In contrast, the phosphorylation of STAT5 was inhibited by 10 only with an $I C_{50}$ value of $>100 \mu \mathrm{m}$. We suspected that the low cellular activity of $\mathbf{1 0}$ was hampered by low cellular uptake owing to its high polarity. This suspicion was substantiated by the higher activity of ester derivative 18, which might act as prodrug being activated by intracellular esterases $24,33,39$. A time course experiment indeed showed that compound $\mathbf{1 8}$ reduced STAT5 phosphorylation steadily over $10 \mathrm{~h}$ (Supplementary Figure 5). Both compounds $\mathbf{1 6}$ and 18 had no effect on the overall expression of endogenous STAT5 (Supplementary Figure 5).

Next, inhibition of gene transcription by $\mathbf{1 6}$ was determined. BaF3/FLT3-ITD cells transfected with a dual firefly/Renilla luciferase system were treated with $\mathbf{1 6}$ for $6 \mathrm{~h}$ and the activity of the STAT5-transcribed luciferase reporter gene was found to reduce significantly in a dose-dependent manner (Fig. 5b). Inhibition of the endogenous transcription of STAT5 target genes by 16 and 18 was studied, too. BaF3/FLT3-ITD cells were treated with inhibitors for $6 \mathrm{~h}$, mRNA was harvested and analyzed by quantitative RT-PCR. Transcription and protein expression of three target genes of STAT5, Pim1 kinase, Bcl-xl, and Cis, which play essential roles in cell cycle progression and survival, was found to be strongly reduced (Fig. 5c, Supplementary Figure 5).

The effect of STAT5 inhibitors 10, 16, and $\mathbf{1 8}$ on the proliferation of cancer cells carrying the common FLT3-ITD mutation after $48 \mathrm{~h}$ was quantified by the Alamar Blue assay (Fig. 5d). All three compounds showed a clear dose-dependent inhibition of cell proliferation. For comparison, the compounds were tested with four non-STAT5-dependent cell lines (HT-29, COS-7, HeLa and MDA-MB-231) and here cytotoxicity was negligible at up to $500 \mu \mathrm{M}$ (Supplementary Figure 6). The compounds also showed no effects on STAT3 phosphorylation and on endogenous STAT3 expression (Supplementary Figures 5 and 6$)^{25}$. The percentage of necrotic vs. apoptotic cells death after treatment with $\mathbf{1 6}$ was studied by flow cytometry staining with a fluorescent annexin-V conjugate and with propidium iodide (PI), likewise reduced STAT5 phosphorylation was studied using a 
a
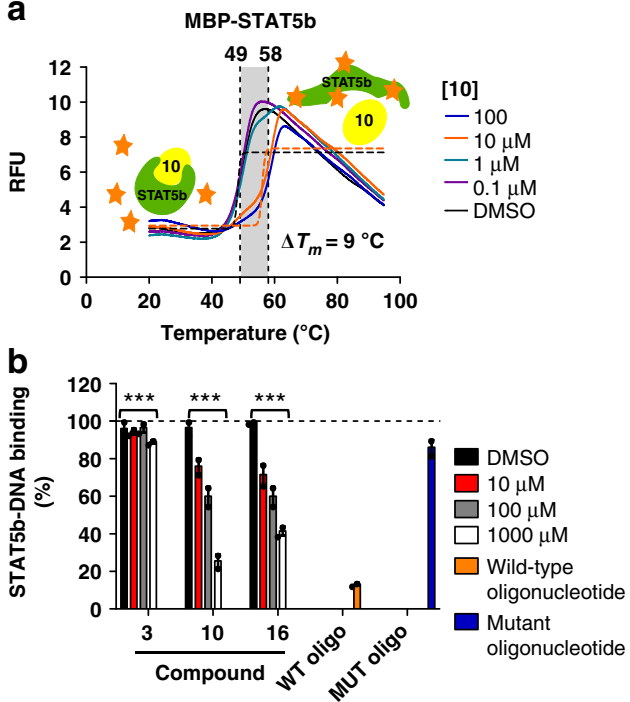

d
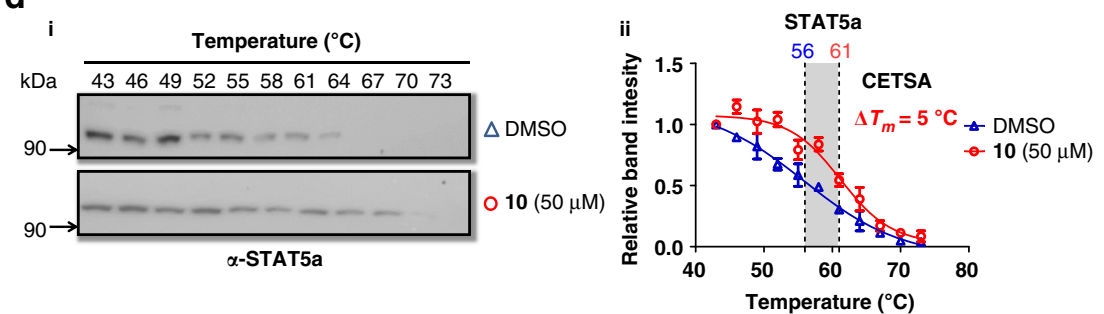

e $\mathbf{i}$
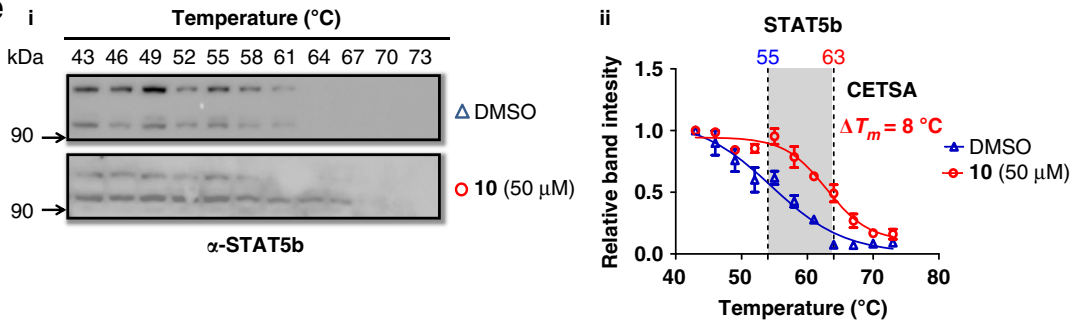

C
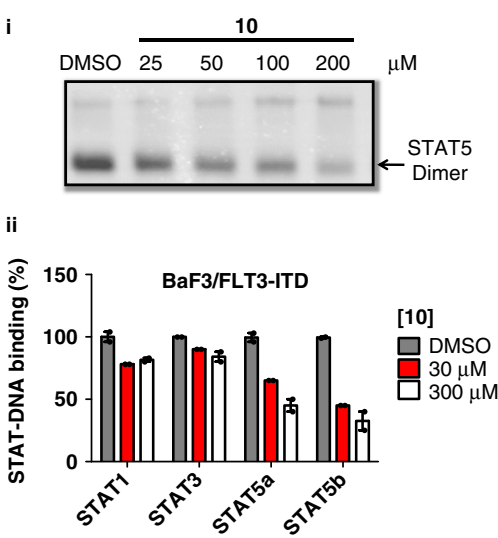

f i Incubation at room temperature, $1 \mathrm{~h}$

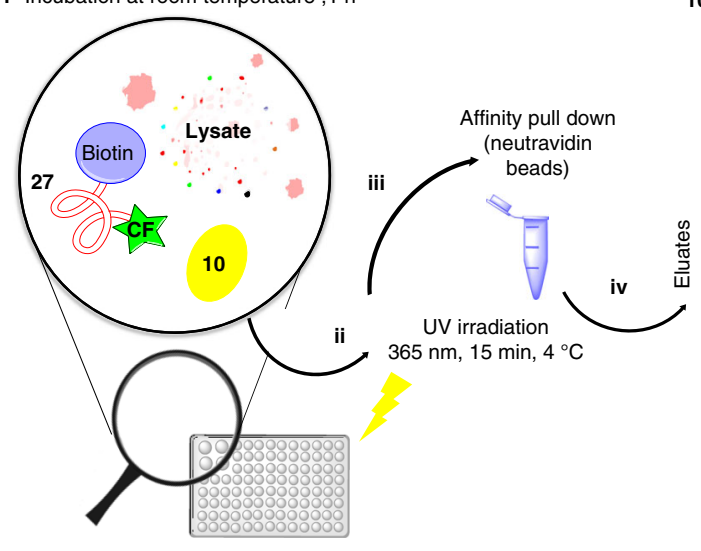

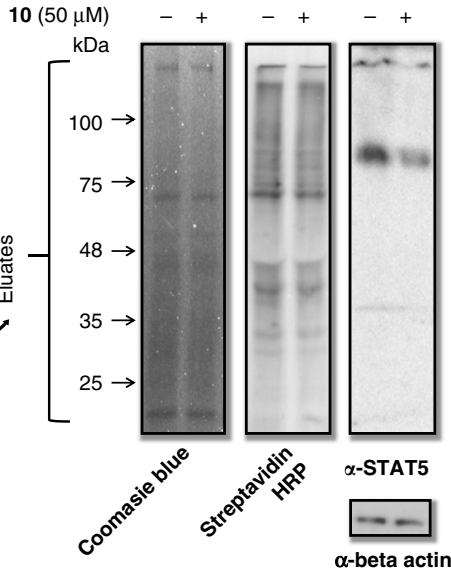

STAT family members

Fig. 4 Inhibitor 10 blocks STAT5 dimerization, DNA-binding, and is active in CETSA and photocrosslinking assays in cellular lysates. a $\mathbf{1 0}$ stabilizes MBP-STAT5b-SH2 shifting the melting temperature $\left(\Delta T_{m}\right)$ by $9{ }^{\circ} \mathrm{C}$ in the TSA (data shown are one representative example of $n=3$ ). $\mathbf{b} \mathbf{1 0}$ and $\mathbf{1 6}$ inhibit formation of trimeric (STAT5b) 2 -DNA complexes in an ELISA $(n=3)$. c (i) 10 inhibits binding of STAT5 dimers, isolated from nuclear extracts of BaF3/ FLT3-ITD cells, to its target DNA in the electro mobility shift assay (EMSA) and (ii) shows selectivity for disrupting STAT5a,b-DNA complexes in the TransAM ${ }^{\oplus}$ STAT family ELISA $(n=3)$. d-e 10 binds to STAT5a and STAT5b in complex cellular lysates as demonstrated by cellular TSA (CETSA), resulting in shifted melting curves at $50 \mu \mathrm{M}$ compared with vehicle (DMSO). Relative STAT5a and STAT5b band intensities were plotted against corresponding incubation temperatures and fitted to Boltzmann sigmoidal curve. The blue triangle represents DMSO and red circle represents compound $\mathbf{1 0}(n=3$ ). f Binding of $\mathbf{1 0}$ to STAT5 in BaF3/FLT3-ITD cell lysate was determined by photo-crosslinking $(n=3)$. (i) The dual-labeled (carboxyfluorescein and biotin) peptide probe $\mathbf{2 7}$ binds to STAT5 with submicromolar affinity and photocrosslinked (ii) with target proteins by activating the 4-phosphoncarbonyl residue that acts as a photoactive phosphotyrosine-mimetic. (iii) Cross-linked proteins can be isolated by biotin pull-down using Neutravidine beads. (iv) Displacement of $\mathbf{2 7}(100 \mu \mathrm{M})$ by compound $\mathbf{1 0}(50 \mu \mathrm{m})$ in BaF3/FLT3-ITD cell lysates $\left(1 \mathrm{mg} \mathrm{ml}^{-1}\right)$ resulted in significantly reduced photo-crosslinking of $\mathbf{2 7}$ and STAT5 as demonstrated in the western blotting using STAT5 antibodies (right lane), whereas other biotinylated proteins were not reduced (middle lane). For an uncropped image of $\mathbf{c}, \mathbf{d}, \mathbf{e}, \mathbf{f}$ see Supplementary Figure 10. Error bars denote mean \pm S.D. and $p$ values are considered as follows: ${ }^{\star} p$ value $<$ $0.05 ;{ }^{\star \star} p$ value $<0.01$; and ${ }^{\star \star \star} p$ value $<0.001$. Statistical analyses were performed using one-way ANOVA or the two-tailed Student's $t$ tests where appropriate

fluorophor-conjugated anti-pSTAT5 antibody (PE-Cy7 Mouse anti-STAT5, pY694, Fig. 5e).

Target specificity of compound $\mathbf{1 6}$ to STAT5 in living cells was evaluated using isothermal dose-response fingerprints (ITDRF) ${ }^{40}$, a variation of CETSA experiments. BaF3/FLT3-ITD cells were treated with 16 at concentrations between 0 and $100 \mu \mathrm{m}$ for $6 \mathrm{~h}$. All samples were heated for $3 \mathrm{~min}$ to $60^{\circ} \mathrm{C}$, the denaturation temperature based on the $T_{m}$ curves in the CETSA experiment (Fig. 4d, e), lyzed and immunoblotted with STAT5a/b antibodies. The amount of STAT5 protein found in the blot was plotted against logarithmic concentration of the inhibitor, indicating the in-cell occupancy $\left(O C_{50}\right)$ of STAT5a/b of 63 and $28 \mu \mathrm{m}$, respectively, correlating well with the inhibition of target phosphorylation and cell proliferation (Fig. 5f, g).

Moreover, the synergistic effects of STAT5 inhibitor $\mathbf{1 6}$ with the staurosporine-derived FLT3-inhibitor PKC412 were investigated ${ }^{41,42}$. The receptor tyrosine kinase FLT3 and especially the constitutively activated mutant FLT3-ITD have been described to be responsible for the phosphorylation and, thereby, overactivation of STAT5. Treatment of AML patients 
a

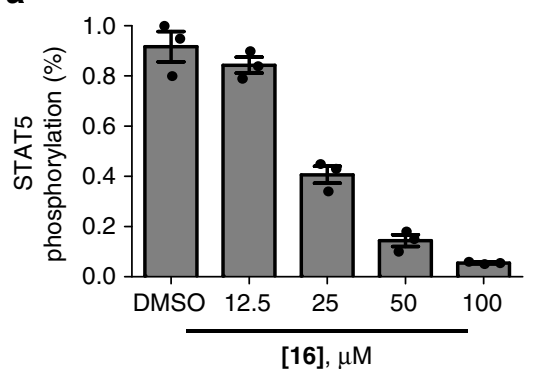

C

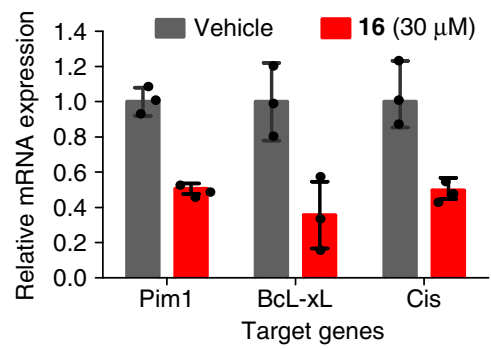

b

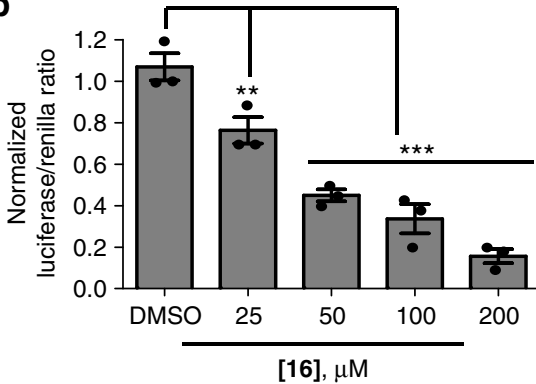

d

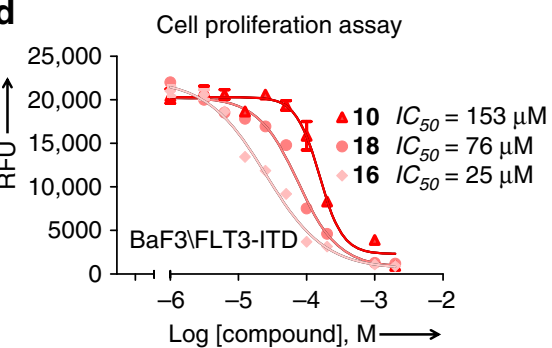

[16]

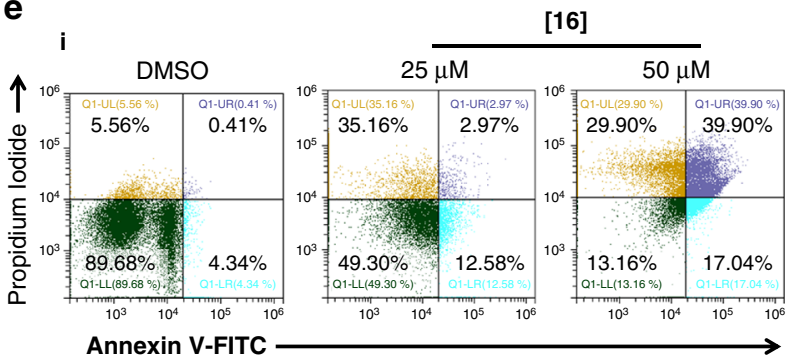

ii

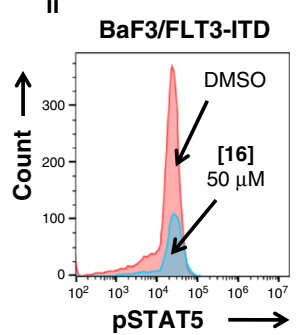

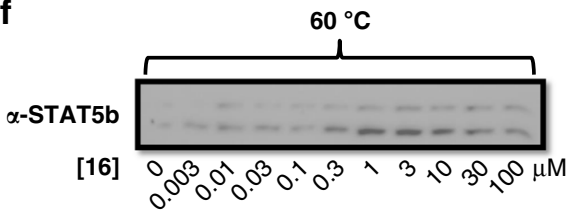

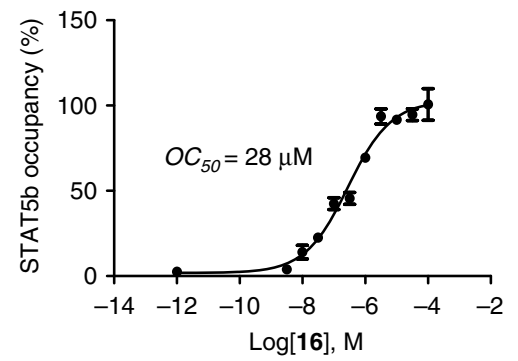

g

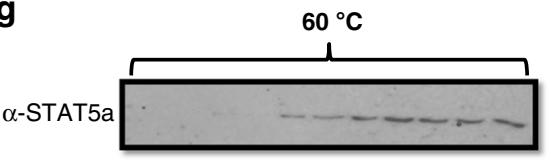

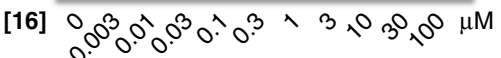

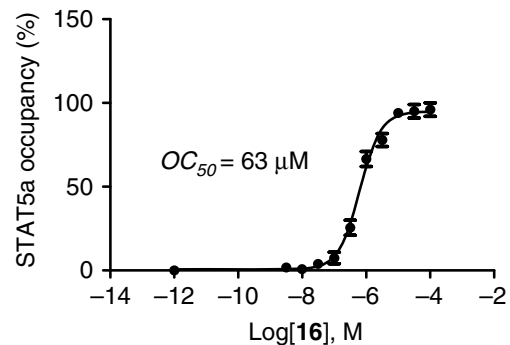

Fig. 5 Activity, target occupancy, and functional effects of STAT5 inhibitor $\mathbf{1 6}$ tested in STAT5-dependent cells. a $\mathbf{1 6}$ blocks tyrosine phosphorylation of STAT5 in a dose-dependent manner as shown by western blot analysis in BaF3/FLT3-ITD cells after $6 \mathrm{~h}$ treatment. Relative STAT5 phosphorylation levels were plotted as after quantification using Image J software. Immunoblotting for beta-actin was used as a control for uniform protein loading $(n=3)$. b Compound $\mathbf{1 6}$ inhibits transcriptional activity of STAT5 in BaF3/FLT3-ITD cells as measured by normalized Fluc/Rluc ratio in dual luciferase reporter assay $(n=3)$. c Expression of downstream targets of STAT5 Pim1,BcL-xL and Cis was reduced after $18 \mathrm{~h}$ of treatment with compound $\mathbf{1 6}$. Gene expression was quantified by quantitative PCR $(n=3)$. $\mathbf{d}$ Compound $\mathbf{1 6}$ inhibits the proliferation of BaF3/FLT3-ITD cells after $48 \mathrm{~h}$ as determined by the Alamar Blue assay $(n=3)$. e, i BaF3/FLT3-ITD cells were treated with compound $\mathbf{1 6}$ after which annexin-V/propidium iodide staining and flow cytometry were performed (gating strategy as in Supplementary Figure 11a, data shown are one representative of $n=3$ ); (ii) Intracellular levels of phosphorylated STAT5 were evaluated by flow cytometry after $\mathbf{6 h}$ exposure of cells to compound $\mathbf{1 6}$ for $50 \mu \mathrm{m}$ (gating strategy as in Supplementary Figure 11b, data shown are one representative of $n=3$ ). $\mathbf{f}-\mathbf{g}$, In-cell occupancy of STAT5a and STAT5b by compound $\mathbf{1 6}$ in BaF3/FLT3-ITD, determined using ITDRF. ITDRF of compound 16 on STAT5a and STAT5b denaturization at $60^{\circ} \mathrm{C}$ for 3 min based on raw data from western blotting chemiluminescence readings $(n=3$ ). CETSA, cellular thermal shift assay; ITDRF, isothermal dose-response fingerprint; OC $_{50}$, the concentration at which $50 \%$ of the STAT5 in the cell was occupied by inhibitor. For an uncropped image of panels $\mathbf{f}$ and $\mathbf{g}$ see Supplementary Figure 10. Error bars denote mean \pm S.D. and $p$ values are considered as follows: ${ }^{\star \star} p$ value $<0.01$; and ${ }^{\star \star \star} p$ value $<0.001$. Statistical analyses were performed using one-way ANOVA or the two-tailed Student's $t$ tests where appropriate

bearing the FLT3 mutation with PKC412 alone exhibited a therapeutic effect, however, often led to major drawbacks such as incomplete target inhibition and short-lived responses. Therefore, combination treatment of leukemic cells with two inhibitors, one targeting FLT3 and the other STAT5, can be a promising strategy to enhance inhibition of STAT5 signaling, overcome or prevent resistance toward kinase inhibitors and improve treatment efficacy ${ }^{38,41}$. MV-411 leukemic cells were treated with concentrations of inhibitors resulting in $20 \%$ of cell apoptosis individually as well as in combination. The combination of 16 and PKC412 resulted in a threefold increase in annexin-V-staining corresponding to $60 \%$ apoptotic cells, in decreased reporter gene expression, and in reduced STAT5 phosphorylation (Fig. 6a-d). Both compounds impaired synergistically the cell proliferation after $48 \mathrm{~h}$ of treatment as demonstrated by a Chou-Talalay combination index (CI) plot (Fig. 6c $)^{43}$. For example, the $I C_{50}$ of compound 16 was reduced threefold in the presence of $1.25 \mathrm{~nm}\left(I C_{10}\right)$ of PKC412.

Finally, the inhibitory effect of $\mathbf{1 6}$ was examined in a murine xenograft model of leukemia. Treatment of nude mice with $\mathbf{1 6}$ was tolerated well and had no significant effect on mice body weight (Fig. 6e). Nude mice were inoculated subcutaneously with BaF3/FLT3-ITD cells. The control group displayed rapid tumor growth, while tumor growth in the group treated s.c. with compound 16 (200 $\mathrm{mg} \mathrm{kg}^{-1}$ ) was delayed and became first apparent on day 11 (Fig. 6f). Tumor growth in the treated group was reduced to $6 \% \mathrm{~T} / \mathrm{C}$ on day 11 and $28 \%$ on day 14 proving that compound 16 exhibited anti-tumor efficacy in vivo. 
a

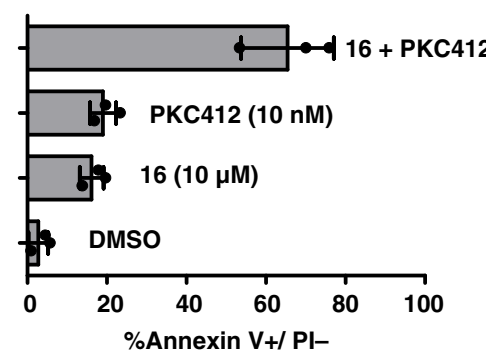

b

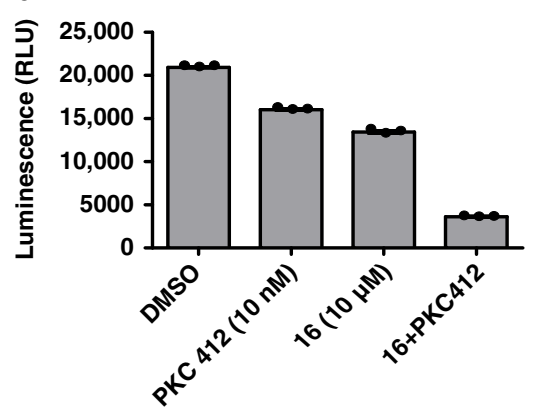

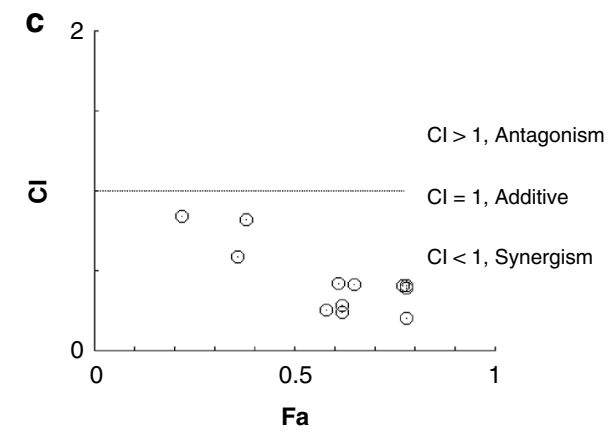

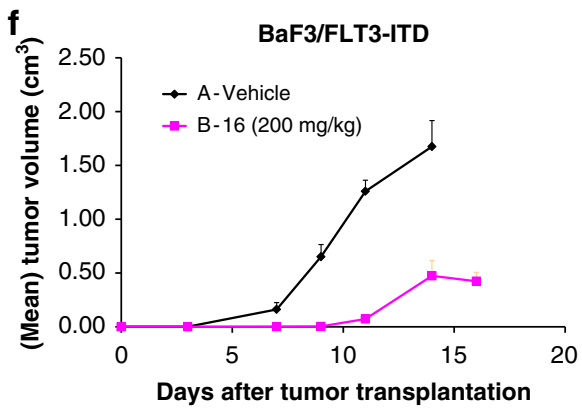

d

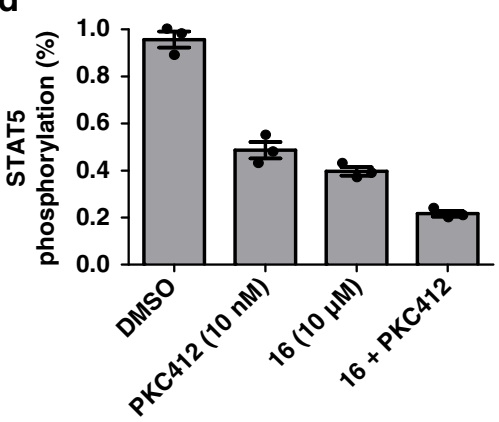

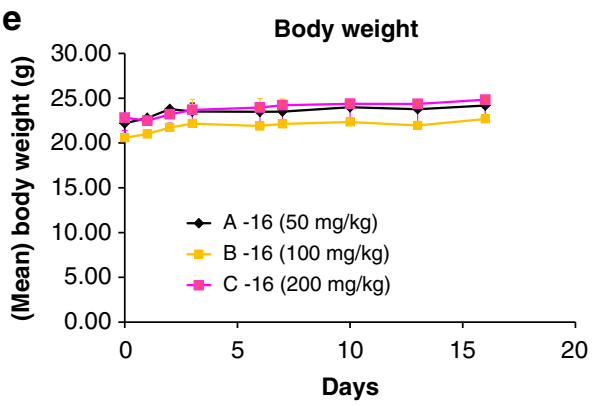

Fig. 6 Synergy of inhibitor $\mathbf{1 6}$ and kinase inhibitor midostaurin (PKC412). Activity tested in a murine cancer model. a MV-411 cells were treated with PKC412 (10 nM) or compound $16(10 \mu \mathrm{m})$ alone or in combination and incubated for $24 \mathrm{~h}$ followed by annexin-V/ propidium iodide staining and flow cytometry. Apoptosis was quantitated for three independent experiments $(n=3)$ and error bars denote mean \pm S.D. b Cell viability assays were carried out by treating MV-411 cells with compound $\mathbf{1 6}(10 \mu \mathrm{m})$ and PKC412 (10 nM) alone or in combination. The number of viable cells was distinguished using an ATP-dependent bioluminescence assay (CellTiter-Glo, Promega) $(n=3$, error bars denote mean \pm S.D.). c Combination index (Cl) plot showing the synergistic effect of compound $\mathbf{1 6}$ and PKC412 in MV-411 cells. Cl values were generated using CalcuSyn software (Conservion, Ferguson, MO) and plotted as a function of fractional growth inhibition $(n=3)(F a)$ where $F a=\left(A_{570}\right.$ control- $A_{570}$ treated $) / A_{570}$ control. $C l$ values of $<1,=1$, and $>1$ indicate synergism, additivity, and antagonism, respectively. Error bars denote mean \pm S.D. d Relative STAT5 phosphorylation levels were plotted based on the raw data from western blotting chemiluminescence readings to study the synergistic effect of both compounds on STAT5 phosphorylation reduction. MV-411 cells were treated with compound $\mathbf{1 6}$ or PKC412 alone or in combination and incubated for $6 \mathrm{~h}$ ( $n=3$, error bars denote mean \pm S.D.). e The corresponding body weight changes in non-xenografted mice during compound $\mathbf{1 6}$ treatments ( $n=6$, error bars denote mean \pm S.D.). $\mathbf{f}$ Compound $\mathbf{1 6}$ significantly inhibits tumor growth in BaF3/FLT3-ITD xenograft tumor model. Time course of tumor growth suppressed by compound 16 (200 $\left.\mathrm{mg} \mathrm{kg}^{-1}\right)$ in mice bearing BaF3/ FLT3-ITD tumor ( $n=6$, error bars denote mean \pm S.D.)

\section{Discussion}

In this contribution, protein-induced Mannich ligations have been discovered and characterized as protein-catalyzed, nonenzymatic reactions following a fundamental mechanism for the formation and identification of protein ligands. The reactions delivered potent, specific, and cellularly active inhibitors of the transcription factor STAT5. The starting point, phosphatemimetic fragment 3 was activated by the protein STAT5b-SH2 enabling three-component reactions with $\mathrm{FA}$ and various $1 H$-tetrazoles in aqueous physiological buffer yielding lowmicromolar and submicromolar inhibitors of the protein-protein interaction site. The progress of the observed Mannich ligations depended on the $\mathrm{pH}$ of the solution and on the presence of the protein. At $\mathrm{pH} 7.4$, the reaction occurred only in the presence of the protein, whereas at $\mathrm{pH} 5.0$ it was switched to an entirely protein-independent reaction. Protein-induced reactions were analyzed using FP and TS assays; products formed were quantified by HPLC-MS and protein-induced product was saturated at $432 \mathrm{~nm}$ (average of three independent experiments) with $250 \mathrm{~nm}$ protein. Product saturation is typical for proteindependent reactions and resulted from auto-inhibition by the products formed. The reaction was also inhibited competitively by alternative ligands of the $\mathrm{SH} 2$ domain confirming that the phosphotyrosine recognition site constituted the catalytic center.

Remarkably, all initial $1 H$-tetrazole fragments like compound 25 did not bind to the STAT5b-SH2 protein at all $\left(K_{I}>10 \mathrm{~mm}\right)$, whereas, for example, the ligation product of $\mathbf{3}, \mathrm{FA}$, and $\mathbf{2 5}$, namely 4-(1H-tetrazol-1-yl)-methylamino-furazan-3-carboxylate 10, displayed super-additive binding with an affinity of $1.4 \mu \mathrm{M}$ and the enhanced ligand efficiency of $2.23 \mathrm{~kJ} \mathrm{~mol}^{-1}$ per nonhydrogen atom. This findings excluded the mechanism of a protein-templated reaction, which requires the binding of both fragments to the protein template in order to initiate the reaction. Instead, an alternative mechanism of protein-dependent reactions was observed, in which only one of the starting molecules, here fragment 3, binds to the protein. Molecular modeling suggested that H-bonding by the side chain amide of Asn642 induced the reaction of fragment 3 with $\mathrm{FA}$, that of the intermediary formiminium ion with tetrazoles, and the high selectivity of the reactions $^{21}$. This hypothesis was challenged by investigating the protein-dependent reaction of 3, FA, and $1 H$-tetrazole with the phosphotyrosine binding site of STAT3-SH2, which is structurally closely related containing Arg618 and Ser622 but lacks Asn642. Indeed STAT3-SH2 did not catalyze the Mannich ligation reaction and no product was identified in HPLC-MS. In agreement with this result, STAT3, STAT1, and the protein tyrosine phosphatase SHP2, all lacking the Asn-residue in the phosphotyrosine recognition sites, did not bind the STAT5 inhibitors 10 and 16, although cross-reactivity has been reported for other STAT-inhibitors ${ }^{4,45}$. The importance of Asn642 was further confirmed by the mutant STAT5b-N642A, which was generated by site-directed mutagenesis. The mutant protein 
displayed strongly reduced binding affinity to peptide $\mathbf{1}$ and to inhibitor $\mathbf{1 0}$ and did not catalyze a Mannich ligation reaction as shown for the wildtype protein. In conclusion, the observed protein-dependent reaction constitutes indeed a protein-induced reaction in which the protein catalytically activates the bound fragment 3 by specific binding interactions without templating the reacting fragments priorly.

Specificity of the formed inhibitors for STAT5 was also confirmed in complex cellular systems. Binding of inhibitors 10 and 16 to STAT5a,b in cell lysates was determined by CETSA. The high selectivity of the protein-ligand interaction was demonstrated by the fact that inhibitor $\mathbf{1 0}$ in cell lysates suppressed photo-crosslinking of the biotinylated STAT5 ligand 27 with STAT5 but not with other proteins. In addition, the selectivity of compound $\mathbf{1 6}$ in living cells was proven by ITDRF. It was found that $50 \%$ of the target proteins STAT5a and b were occupied in living cells with 16 at concentrations $\left(O C_{50}\right.$ values) being in the same range as the $I C_{50}$ values observed for the inhibition of STAT5 phosphorylation and cell proliferation, indicating that the interaction of $\mathbf{1 6}$ with the target STAT5 alone was sufficient to generate and explain the observed biological effects. Likewise, compound 16 was able to block STAT5 transcription and to inhibit cellular proliferation of cancer cells in a mouse model. Another proof for the cellular selectivity of $\mathbf{1 6}$ for STAT5 was that the proliferation of all tested cell lines which proliferate independently from STAT5 activation was not inhibited by $\mathbf{1 6}$ and these cells showed no sign of toxicity.

Our work demonstrates the growing power of proteindependent fragment ligations in fragment-based drug discovery. Protein-induced multicomponent reactions such as Mannich ligations enlarge the chemical diversity of protein ligands accessible by the method considerably. Protein-induced fragment ligations seem to be especially advantageous for the formation of potent and specific ligands as molecular interactions responsible for binding catalyze the ligation reaction. Considering the omnipresence of FA in living cells ${ }^{46,47}$ and the versatility of reactions this and other aldehydes can undergo, the mechanism should find broad application on numerous protein targets and many bioactive fragments should be expandable to chemically diverse and potent protein ligands, possibly even in living cells. Thus, protein-induced reactions seem to constitute an additional, non-enzymatic mechanism exerted by proteins enabling the molecular evolution of ligands and modulating protein activities and functions.

\section{Methods}

General methods. Protocols and reaction schemes for the chemical synthesis of compounds 1-27 as well as other methodological information are reported in the Supplementary Methods. Identity and purity ( $>95 \%$ ) of all compounds were determined by chromatography (silica or RP-18 HPLC), by fully assigned 1Hand 13C-NMR spectra, by high-resolution mass spectra and by elemental analysis.

Antibodies and reagents. The following antibodies were used for immunoblotting: anti-STAT5a (C-6, cat. sc271542, $1 \mu \mathrm{g} \mathrm{ml}^{-1}$ ) and STAT5b (G-2, cat. sc-1656, $1 \mu \mathrm{g} \mathrm{ml}^{-1}$ ), anti-STAT3 (C-20, cat. sc-482, $1 \mu \mathrm{g} \mathrm{ml}^{-1}$ ), anti-phospho-STAT3 (Tyr 705) (cat. sc-7993, $\left.1 \mu \mathrm{g} \mathrm{ml}^{-1}\right)$, anti-STAT5 (C-17, cat. sc-835, $1 \mu \mathrm{g} \mathrm{ml}^{-1}$ ), and anti-Bcl-xL (H-5, cat. sc-8392, $1 \mu \mathrm{g} \mathrm{ml}^{-1}$ ) were obtained from Santa Cruz Biotechnology (Santa Cruz, CA). Antibodies recognizing Cyclin D1 (92G2, cat. 2978 s, $2 \mu \mathrm{g} \mathrm{m}^{-1}$ ), FLT3 (8F2, cat. $3462 \mathrm{~s}, 1 \mu \mathrm{g} \mathrm{ml}^{-1}$ ), phospho-STAT5 (Tyr694) (cat. 9351, $1 \mu \mathrm{g} \mathrm{ml}^{-1}$ ), phospho-FLT3 Tyr591 (cat. $3461 \mathrm{~s}, 1 \mu \mathrm{g} \mathrm{ml}^{-1}$ ) were obtained from Cell Signaling Technology (Danvers, MA). Anti-Pim1 (M08, clone 1C10, cat. H00005292-M08, $2 \mu \mathrm{g} \mathrm{ml}^{-1}$ ) was purchased from Abnova (Taiwan), anti-Betaactin (cat. ab8227, $0.5 \mu \mathrm{g} \mathrm{ml}^{-1}$ ) was from Abcam (Cambridge, MA), anti Biotin-Peroxidase antibody (cat. A4541, $1 \mu \mathrm{g} \mathrm{ml}^{-1}$ ) was obtained from SigmaAldrich (Taufkirchen, Germany) and anti-CIS (cat. PA5-27128, $1 \mu \mathrm{g} \mathrm{ml}^{-1}$ ) was from Thermo Fisher Scientific (Braunschweig, Germany). For phospho flow cytometry experiments, PE-Cy 7 mouse anti-Stat5 (pY694) (clone 47, cat. 560117, $20 \mu \mathrm{l}$ each test) and anti-mouse IgG1 monoclonal antibody (clone A85-1, cat. $550083,0.2 \mu \mathrm{g} \mathrm{ml}^{-1}$ ) were from BD Biosciences. Antibodies were validated by the manufacturers. Recombinant mouse IL3 protein (cat. PMC0034, $1 \mathrm{ng} \mathrm{ml}^{-1}$ ) was purchased from Thermo Fisher Scientific and midostaurin hydrate (PKC412, cat. M1323) was from Sigma-Aldrich. Both TransAM STAT family kit (cat. 42296) and nuclear extraction kit (cat. 40010) were from Active Motif (Carlsbad, CA, USA).

Cell lines and cell culture. MV-411 (CRL-9591) and K562 (CCL-243) cells were from American Type Culture Collection (ATCC), (LGC Standards GmbH, Wesel, Germany). BaF3 and BaF3/FLT3-ITD cells were kind gifts from professor Carol Stocking (University Hospital Hamburg-Eppendorf). All suspension cells were cultured in Rosewell Park Memorial Institute media supplemented with $10 \%$ fetal calf serum (FCS) without or without recombinant mouse IL3 $\left(1 \mathrm{ng} \mathrm{ml}^{-1}\right)$. COS-7 (CRL-1651), HeLa (CCL-2), MDA-MB-231 (HTB-26), and HT-29 (HTB-38) were from and certified by ATCC and cultured in DMEM media supplemented with $10 \%$ FCS. Cell culture media and FCS were purchased from Biozol (Biozol, Eching, Germany). Cells were incubated at $37^{\circ} \mathrm{C}, 5 \% \mathrm{CO}_{2}$ atmosphere. All cell lines were tested and were mycoplasma-free using MycoAlert Mycoplasma Detection Kit (Lonza).

Detection of protein-induced ligand formation via FP assay. All FP assays were conducted in a total volume of $20 \mu \mathrm{l}$ in $50 \mathrm{~mm}$ of MOPS buffer ( $\mathrm{pH} 7.4$ ) at room temperature. For investigating the tolerance of the assay for FA, serial dilutions of FA (concentration range: $0-1 \mathrm{mM}$ ) were prepared and incubated with $250 \mathrm{nM}$ of MBP-STAT5b in buffer. For the protein-induced reaction, 250 nм of MBP-STAT5b protein were added to a mixture of $250 \mu \mathrm{M}$ of $\mathbf{3}$ and one heteraryl nucleophile per microtiter plate well with increasing concentration of FA up to the concentration of $250 \mu \mathrm{M}$. Reaction mixtures were incubated for $12 \mathrm{~h}$ with mild shaking. Plates were centrifuged and $10 \mathrm{~nm}$ of FP probe 1 were added and incubated for $1 \mathrm{~h}$ with mild shaking before measurement with Safire ${ }^{2}$ well plate reader (Tecan, Crailsheim, Germany).

Detection of protein-induced ligand formation via TSA. Here we introduced the possibility of using TSA ${ }^{48}$ assay to determine protein-induced ligand formation. The compatibility of FA with the TSA was investigated using MBP-STAT5b-SH2 protein $(500 \mathrm{nM})$ mixed with increasing concentrations of FA up to the concentration of $250 \mu \mathrm{M}$ and incubated at room temperature with mild shaking in a sealed 384 PCR plate. To determine the formation of ligand via a protein-induced reaction, MBP-STAT5b-SH2 protein $500 \mathrm{~nm}$ was added to $250 \mu \mathrm{M}\left(\mathrm{IC}_{20}\right) 4$-aminofurazane-3-carboxylic acid 3, equimolar amount $(250 \mu \mathrm{M})$ of one heteraryl nucleophile per PCR plate well with increasing concentration of FA up to the concentration of $250 \mu \mathrm{M}$. Reaction mixtures were incubated for $12 \mathrm{~h}$ with mild shaking at room temperature, respectively. After $12 \mathrm{~h}$, the plates were centrifuged and $1 \mu \mathrm{l}$ of $400 \mathrm{X}$ Sypro Orange solution (Thermo Scientific) was added, resulting in a total assay volume of $20 \mu \mathrm{l}$, with a final protein concentration of $475 \mathrm{~nm}$. The PCR plates were again sealed with optical seal, shaken for $15 \mathrm{~min}$, and centrifuged. Thermal scanning $\left(20-95^{\circ} \mathrm{C}\right.$ at $\left.1{ }^{\circ} \mathrm{C} \mathrm{min}-1\right)$ was performed using a real-time PCR setup (LightCycler (Roche Diagnostics, Mannheim, Germany) and fluorescence intensity was measured after every $0.3 \mathrm{~s}$. Curve fitting, melting temperature calculation, and report generation on the raw data were performed using GraphPad Prism 5 software.

Detection of protein-induced ligand formation by LC/MS. Extracted ion chromatography was performed with reaction mixtures containing $250 \mathrm{nM}$ of MBP-STAT5b protein, $250 \mu \mathrm{M}\left(\mathrm{IC}_{20}\right)$ 4-amino-furazane-3-carboxylic acid 3, equimolar amount $(250 \mu \mathrm{M})$ of one heteraryl nucleophile and FA with a total volume of $100 \mu \mathrm{l}$. The reaction mixtures were vortexed to mix thoroughly and incubated overnight at room temperature and was analyzed using a HPLC/QTOFMS instrument by Agilent, consisting of an Infinity 1290 UHPLC coupled to a 6550 iFunnel QTOF. After $12 \mathrm{~h}$ each sample was analyzed in triplicate by injecting $(10 \mu \mathrm{l})$ into the LC/MS instrument and the ligation products were identified by their molecular weights and by comparison of the retention times of synthetic reference. Calibration curves for hit compounds $\mathbf{1 0}$ and $\mathbf{1 6}$ are given in Supplementary Figure 19.

Determination of STAT-DNA binding using ELISA. Binding of STAT1, STAT3 STAT5a, and b to DNA was determined from nuclear protein extracts using the TransAM STAT family kit from Active Motif (Carlsbad, CA). Nuclear protein extract was prepared by resuspending nuclear pellet by pipetting up and down in $50 \mu \mathrm{l}$ of complete lysis buffer (Active Motif, Carlsbad,CA) in the presence of $2.5 \mu \mathrm{l}$ of detergent to ease solubilization of membrane associated nuclear proteins. Suspension was incubated on ice for $30 \mathrm{~min}$ on a rocking platform at $150 \mathrm{rpm}$ followed by $30 \mathrm{~s}$ vortex at highest setting. Nuclear extract fraction was collected through centrifugation at $14,000 \times g$ and protein concentration was determined using Bradford assay. Nuclear extract $\left(2 \mu \mathrm{l}\right.$ of a $1 \mu \mathrm{g}^{-1}$ solution) containing activated, dimeric STAT was dissolved in a mixture of a solution of the inhibitor 3, 10, or 16 in complete lysis buffer $(20 \mu \mathrm{l}, 1 \%(\mathrm{v} / \mathrm{v})$ DMSO) and complete binding buffer $(30 \mu \mathrm{l})$ in microtiter wells coated with DNA of the respective STAT consensus sequence. After incubation at room temperature for $1 \mathrm{~h}$, the wells were washed three times with the wash buffer and incubated with respective STAT antibodies for $1 \mathrm{~h}$. After washing as before, wells were incubated with a secondary antibody 
conjugated to horseradish peroxidase for $1 \mathrm{~h}$ at room temperature. Wells were washed again for three times, incubated with $100 \mu \mathrm{l}$ of developing solution, quenched with $100 \mu \mathrm{l}$ of the stop solution, and the absorbance was measured at $450 \mathrm{~nm}$ using Safire ${ }^{2}$ well plate reader (Tecan, Crailsheim, Germany).

EMSA. Gel shift assay was conducted using a double-stranded, biotin-labeled oligonucleotide probe containing the consensus binding site for STAT5 (sense strand, $5^{\prime}$-AGATTTCTAGGAATTCAATCC-3'), using the Gelshift Chemiluminescent EMSA kit (Active Motif). In brief, protein-DNA complexes were resolved on a nondenaturing polyacrylamide gel, transferred to a positively charged nylon membrane, and cross-linked to the membrane using the UV-light cross-linker. After blocking, the membrane was incubated with blocking buffer containing streptavidin conjugated to HRP. After washing, protein-DNA complexes were detected using a chemiluminescent substrate (Active Motif, Carlsbad, CA, USA) 40,49

Photo-crosslinking and enrichment of biotinylated proteins. Peptide probe $27(100 \mu \mathrm{M})$ was incubated with BaF3/FLT3-ITD whole cell lysates $(1 \mathrm{ml}$ of $1 \mathrm{mg}$ $\mathrm{ml}^{-1}$ ) in the binding buffer (50 mM HEPES, pH 7.5, $200 \mathrm{~mm} \mathrm{NaCl}, 2 \mathrm{~mm}$ $\mathrm{MgCl}_{2}, 0.1 \%$ Tween-20, 20\% glycerol, $2 \mathrm{mM}$ phenylmethylsulfonyl fluoride, Roche Complete ethylenediaminetetraacetic acid-free protease inhibitor cocktail) for $1 \mathrm{~h}$ at $4{ }^{\circ} \mathrm{C}$. The samples were then irradiated at $365 \mathrm{~nm}$ using a UV transilluminator for $15 \mathrm{~min}$ at $4{ }^{\circ} \mathrm{C}$. For competitive displacement studies, compound $10(50 \mu \mathrm{M})$ was added together with peptide probe 27 and incubated with whole cell lysates for $1 \mathrm{~h}$ at $4{ }^{\circ} \mathrm{C}$ prior to UV photo-crosslinking for $15 \mathrm{~min}$ at $4{ }^{\circ} \mathrm{C}$. The mixture was then incubated with Neutravidin agarose resin (Thermo Fisher Scientific) for $2 \mathrm{~h}$ at room temperature. After washing with phosphate-buffered saline with $0.1 \%$ sodium dodecyl sulfate (SDS), the enriched proteins were eluted by boiling the beads in SDS-polyacrylamide gel electrophoresis sample buffer.

Statistical analysis. Statistical calculations were performed using GraphPad Prism 5.01 software and reported as mean \pm S.D. Experiments were performed in triplicates and/or repeated at least three times unless indicated otherwise. Two-tailed Student's $t$ tests and one-way analysis of variance were used to identify statistically significant data. $p$ values are considered as follows: ${ }^{*} p$ value $<0.05 ;{ }^{* *} p$ value $<0.01$; and ${ }^{* * *} p$ value $<0.001$ and statistical significance was attributed to $p$ values $<0.05$. Synergy in cell viability assays was determined by plotting isobolograms and calculating the CI using CalcuSyn software (Calcusyn software, Biosoft, San Diego, CA, USA) (Conservion, Ferguson, $\mathrm{MO}$ ) using the Chou-Talalay method ${ }^{43}$ to ascertain if the effects of drug combinations were synergistic $(C I<1)$, additive $(C I$ $=1)$, or antagonistic $(C I>1)$.

Animal experiments. NSG mice (NOD/Shi-scid/IL-2R $\gamma^{\text {null }}$ ) obtained from The Jackson Laboratory aged 6 weeks with an average body weight of $22 \mathrm{~g}$. All animal experiments have been approved by the Tierversuchskommission (commission for animal experiments) of the Landesamt für Gesundheit und Soziales (LaGeSo, the state office for health and social affairs), which is the responsible ethics committee for all animal experiments conducted in the state of Berlin. All animal experiments were carried out in accordance with the United Kingdom coordinating committee on cancer research regulations for the welfare of animals and with German Animal Protection Law and were reviewed by the animal protection officer (Tierschutzbeauftragter) at Experimental Pharmacology \& Oncology (EPO) Berlin-Buch GmbH. BaF3/FLT3-ITD cells were injected into mice subcutanously $\left(10^{6}\right.$ cells per mouse). Inoculated and control mice (six in each group) were treated for $16 \mathrm{~d}$ once daily s.c. with either the vehicle ( $10 \%(\mathrm{v} / \mathrm{v}) \mathrm{DMSO} / 0.25 \%$ Tween 80$)$ or compound $16\left(200 \mathrm{mg} \mathrm{kg}^{-1}\right)$ dissolved in vehicle, starting shortly after tumor cell inoculation. Former studies had shown that this concentration of test compound is well tolerated by the mice. Tumor volumes and body weights were recorded daily $(n=6$, error bars denote mean \pm S.D.).

Reporting Summary. Further information on experimental design is available in the Nature Research Reporting Summary linked to this article.

\section{Data availability statement}

The authors declare that the data supporting the findings of this study are available within the article and its Supplementary Information files. A reporting summary for this Article is available as a Supplementary Information file. The source data underlying Figs. 3b, 3d, 3f, 4a, 6e, f, and Supplementary Figures 2g-i have been submitted to FigShare: https://figshare.com/s/4a8e28d4337b5509c6ed. All other relevant data supporting the findings of this study are available from the corresponding author upon request.

Received: 17 May 2018 Accepted: 6 December 2018

Published online: 08 January 2019

\section{References}

1. Jaegle, M. et al. Protein-templated fragment ligations - from molecular recognition to drug discovery. Angew. Chem. Int. Ed. 56, 7358-7378 (2017).

2. Herrmann, A. Dynamic combinatorial/covalent chemistry: a tool to read, generate and modulate the bioactivity of compounds and compound mixtures. Chem. Soc. Rev. 43, 1899-1933 (2014).

3. Mondal, M. \& Hirsch, A. K. H. Dynamic combinatorial chemistry: a tool to facilitate the identification of inhibitors for protein targets. Chem. Soc. Rev. 44, 2455-2488 (2015).

4. Ramström, O. \& Lehn, J.-M. Drug discovery by dynamic combinatorial libraries. Nat. Rev. Drug. Discov. 1, 26-36 (2002).

5. Schmidt, M. F., Groves, M. R. \& Rademann, J. Dynamic substrate enhancement for the identification of specific, second-site-binding fragments targeting a set of protein tyrosine phosphatases. Chembiochem 12, 2640-2646 (2011)

6. Jaegle, M., Nawrotzky, E., Wong, E. L., Arkona, C. \& Rademann, J. in Fragment-based Drug Discovery Lessons and Outlook (eds Erlanson, D. A. \& Jahnke, W.) 293-326 (Wiley-VCH Verlag GmbH \& Co. KGaA, 2016).

7. Schmidt, M. F. \& Rademann, J. Dynamic template-assisted strategies in fragment-based drug discovery. Trends Biotechnol. 27, 512-521 (2009).

8. Schmidt, M. F. et al. Sensitized detection of inhibitory fragments and iterative development of non-peptidic protease inhibitors by dynamic ligation screening. Angew. Chem. Int. Ed. 47, 3275-3278 (2008).

9. Burda, E. \& Rademann, J. Catalytic activation of pre-substrates via dynamic fragment assembly on protein templates. Nat. Commun. 5, 5170 (2014).

10. Schmidt, M. F., El-Dahshan, A., Keller, S. \& Rademann, J. Selective identification of cooperatively binding fragments in a high-throughput ligation assay enables development of a picomolar caspase-3 inhibitor. Angew. Chem. Int. Ed. 48, 6346-6349 (2009).

11. Erlanson, D. A. et al. Site-directed ligand discovery. Proc. Natl. Acad. Sci. USA 97, 9367-9372 (2000)

12. Suzuki, T. et al. An unexpected example of protein-templated click chemistry. Angew. Chem. Int. Ed. 49, 6817-6820 (2010).

13. Hu, X., Sun, J., Wang, H.-G. \& Manetsch, R. Bcl-XL-templated assembly of its own protein - protein interaction modulator from fragments decorated with thio acids and sulfonyl azides. J. Am. Chem. Soc. 130, 13820-13821 (2008).

14. Kulkarni, S. S., Hu, X., Doi, K., Wang, H.-G. \& Manetsch, R. Screening of protein-protein interaction modulators via sulfo-click kinetic target-guided synthesis. ACS Chem. Biol. 6, 724-732 (2011).

15. Becker, D. et al. Irreversible inhibitors of the $3 \mathrm{C}$ protease of Coxsackie virus through templated assembly of protein-binding fragments. Nat. Commun. 7, 12761 (2016)

16. Jaegle, M., Steinmetzer, T. \& Rademann, J. Protein-templated formation of an inhibitor of the blood coagulation Factor Xa through a background-free amidation reaction. Angew. Chem. Int. Ed. 56, 3718-3722 (2017).

17. Bar-Natan, M., Nelson, E. A., Xiang, M. \& Frank, D. A. STAT signaling in the pathogenesis and treatment of myeloid malignancies. JAK-STAT 1, 55-64 (2012).

18. Cumaraswamy, A. A., Todic, A., Resetca, D., Minden, M. D. \& Gunning, P. T Inhibitors of Stat5 protein signalling. MedChem Comm 3, 22-27 (2012).

19. Gianti, E. \& Zauhar, R. An SH2 domain model of STAT5 in complex with phospho-peptides define "STAT5-binding signatures". J. Comput. Aided Mol. Des. 25, 1-20 (2015).

20. Liu, S. et al. Targeting STAT5 in hematological malignancies through inhibition of the bromodomain and extra-terminal (BET) bromodomain protein BRD2. Mol. Cancer Ther. 13, 1194-1205 (2014).

21. Horatscheck, A. et al. Benzoylphosphonate-based photoactive phosphopeptide mimetics for modulation of protein tyrosine phosphatases and highly specific labeling of SH2 domains. Angew. Chem. Int. Ed. 51, 9441-9447 (2012).

22. Schust, J., Sperl, B., Hollis, A., Mayer, T. U. \& Berg, T. Stattic: a small-molecule inhibitor of STAT3 activation and dimerization. Chem. Biol. 13, 1235-1242 (2006).

23. Cumaraswamy, A. A. et al. Nanomolar-potency small molecule inhibitor of STAT5 protein. ACS Med. Chem. Lett. 5, 1202-1206 (2014).

24. Elumalai, N., Berg, A., Natarajan, K., Scharow, A. \& Berg, T. Nanomolar inhibitors of the transcription factor STAT5b with high selectivity over STAT5a. Angew. Chem. Int. Ed. 54, 4758-4763 (2015)

25. Page, B. D. G. et al. Small molecule STAT5-SH2 domain inhibitors exhibit potent antileukemia activity. J. Med. Chem. 55, 1047-1055 (2012).

26. Lisurek, M. et al. Design of chemical libraries with potentially bioactive molecules applying a maximum common substructure concept. Mol. Divers. 14, 401-408 (2010).

27. Hopkins, A. L., Keseru, G. M., Leeson, P. D., Rees, D. C. \& Reynolds, C. H. The role of ligand efficiency metrics in drug discovery. Nat. Rev. Drug. Discov. 13, 105-121 (2014). 
28. Fedorov, O., Niesen, F. H. \& Knapp, S. Kinase inhibitor selectivity profiling using differential scanning fluorimetry. Methods Mol. Biol. 795, 109-118 (2012).

29. Niesen, F. H., Berglund, H. \& Vedadi, M. The use of differential scanning fluorimetry to detect ligand interactions that promote protein stability. Nat. Protoc. 2, 2212-2221 (2007).

30. Neculai, D. et al. Structure of the unphosphorylated STAT5a dimer. J. Biol. Chem. 280, 40782-40787 (2005).

31. Barr, A. J. et al. Large-scale structural analysis of the classical human protein tyrosine phosphatome. Cell 136, 352-363 (2009).

32. Hirsch, A. K., Fischer, F. R. \& Diederich, F. Phosphate recognition in structural biology. Angew. Chem. Int. Ed. 46, 338-352 (2007).

33. Elumalai, N. et al. Rational development of Stafib-2: a selective, nanomolar inhibitor of the transcription factor STAT5b. Sci. Rep. 7, 819 (2017).

34. Wingelhofer, B. et al. Pharmacologic inhibition of STAT5 in acute myeloid leukemia. Leukemia 32, 1135-1146 (2018).

35. Almqvist, $H$. et al. CETSA screening identifies known and novel thymidylate synthase inhibitors and slow intracellular activation of 5-fluorouracil. Nat. Commun. 7, 11040 (2016)

36. Molina, D. M. et al. Monitoring drug target engagement in cells and tissues using the cellular thermal shift assay. Science 341, 84-87 (2013).

37. Mizuki, M. et al. Flt3 mutations from patients with acute myeloid leukemia induce transformation of 32D cells mediated by the Ras and STAT5 pathways. Blood 96, 3907-3914 (2000).

38. Kindler, T., Lipka, D. B. \& Fischer, T. FLT3 as a therapeutic target in AML: still challenging after all these years. Blood 116, 5089-5102 (2010).

39. Mandal, P. K. et al. Potent and selective phosphopeptide mimetic prodrugs targeted to the Src Homology 2 (SH2) domain of signal transducer and activator of transcription 3. J. Med. Chem. 54, 3549-3563 (2011).

40. Jafari, R. et al. The cellular thermal shift assay for evaluating drug target interactions in cells. Nat. Protoc. 9, 2100-2122 (2014).

41. Fabbro, D. et al. PKC412-a protein kinase inhibitor with a broad therapeutic potential. Anticancer Drug Des. 15, 17-28 (2000).

42. Weisberg, E. et al. Inhibition of mutant FLT3 receptors in leukemia cells by the small molecule tyrosine kinase inhibitor PKC412. Cancer Cell 1, 433-443 (2002).

43. Chou, T. C. Drug combination studies and their synergy quantification using the Chou-Talalay method. Cancer Res. 70, 440-446 (2010).

44. Croucher, D. C. et al. The potent STAT3/5 Inhibitor, BP-1-102 demonstrates significant anti-tumor activity against Waldenström Macroglobulinemia. Am. Soc. Hematol. 118, 5101-5101 (2011).

45. Lim, J. S. J. et al. Extended cohort study of OPB51602, a novel inhibitor of STAT3/5 activation, in non-small cell lung carcinoma. Am. J. Clin. Oncol. 15, 8028-8028 (2014).

46. Burgos-Barragan, G. et al. Mammals divert endogenous genotoxic formaldehyde into one-carbon metabolism. Nature 548, 549 (2017)

47. Brewer, T. F. \& Chang, C. J. An aza-cope reactivity-based fluorescent probe for imaging formaldehyde in living cells. J. Am. Chem. Soc. 137, 10886-10889 (2015).

48. Krishna, S. N. et al. A fluorescence-based thermal shift assay identifies inhibitors of mitogen activated protein kinase kinase 4. PLOS. ONE 8, e81504 (2013).
49. Qian, Y.-H., Xiao, Q., Chen, H. \& Xu, J. Dexamethasone inhibits camptothecin-induced apoptosis in C6-glioma via activation of Stat5/Bcl-xL pathway. Biochim. Biophys. Acta 1793, 764-771 (2009).

\section{Acknowledgements}

Support is gratefully acknowledged from the Investitionsbank Berlin (grant No. 10142914), the Deutsche Krebshilfe, and the DFG (FOR 806, SFB765, and the Berlin School of Integrative Oncology for a fellowship granted to E.L.W.). We thank Professor Thorsten Berg, University of Leipzig, for the plasmid containing STAT5-MBP and Professor Carol Stocking, University Hospital Hamburg-Eppendorf for providing us with the BaF3/FLT3-ITD cell line. We are grateful to Dr. Anne Diehl, FMP, for protein expression, to Dr. Jens Peter von Kries, FMP, for screening support, to Dr. María Isabel Fernández-Bachiller, FU Berlin, for initial discussion on FP assays, and to Thomas Rudolf, FU Berlin, for supporting chemical synthesis.

\section{Author contributions}

J.R., E.L.W., D.C., and C.A. conceived and designed the experiments, E.L.W., B.G.K., S.B., and X.W. performed the experiments. E.L.W., C.A., M.L., and J.R. analyzed the data E.N., B.G.K., S.B., C.A., and S.W. contributed reagents. J.R. and E.L.W. wrote the manuscript. J.R. acquired funding for and administered the project.

\section{Additional information}

Supplementary Information accompanies this paper at https://doi.org/10.1038/s41467018-07923-2.

Competing interests: The authors declare no competing interests.

Reprints and permission information is available online at http://npg.nature.com/ reprintsandpermissions/

Journal Peer Review Information: Nature Communications thanks the anonymous reviewers for their contribution to the peer review of this work

Publisher's note: Springer Nature remains neutral with regard to jurisdictional claims in published maps and institutional affiliations.

Open Access This article is licensed under a Creative Commons Attribution 4.0 International License, which permits use, sharing, adaptation, distribution and reproduction in any medium or format, as long as you give appropriate credit to the original author(s) and the source, provide a link to the Creative Commons license, and indicate if changes were made. The images or other third party material in this article are included in the article's Creative Commons license, unless indicated otherwise in a credit line to the material. If material is not included in the article's Creative Commons license and your intended use is not permitted by statutory regulation or exceeds the permitted use, you will need to obtain permission directly from the copyright holder. To view a copy of this license, visit http://creativecommons.org/ licenses/by/4.0/

(C) The Author(s) 2019 